\title{
The jaw muscles and central sensitization in migraine
}

SADJ November 2018, Vol. 73 No. 10 p627 - p628

E Shevel

\section{Conflict of interest}

No conflict declared. There was no funding nor was there institutional support.

\section{ABSTRACT \\ Sensitization of the trigeminal subnucleus caudalis $(\mathrm{Vc})$ is an important process in the generation of migraine pain. The role in migraine of afferent input from the jaw muscles in the sensitization of the $V_{c}$ is discussed.}

\section{INTRODUCTION}

This article investigates the evidence for jaw muscle involvement in central sensitization. The importance of central sensitization in migraine has been well-documented. ${ }^{1,2}$ Although it is widely believed that sensitization of meningeal nociceptors is fundamental to the generation of migraine headache, ${ }^{3,4}$ this does not exclude the possibility that migraine pain may originate from other anatomical structures as well. Sensory signals that originate from many structures in the head are processed by Vc neurons. These structures include not only the meninges, but also jaw muscles, facial skin, cornea, hair follicles, and intraand extra-cranial blood vessels. ${ }^{4}$ It follows therefore that input from any of these structures may enhance the sensitivity of the Vc. There is extensive convergence of afferent nerves, including from the jaw muscles, on $V_{c}$ neurones. ${ }^{5}$ A considerable proportion of the wide dynamic range (WDR) and the nociceptive specific (NS) neurones in the $V_{c}$ have afferent inputs from the jaw muscles, ${ }^{6}$ and can be excited by jaw muscle afferent stimuli. ${ }^{7}$ The $V_{c}$ is especially important in pain perception of the jaws and face, ${ }^{8}$ including from convergent cutaneous and jaw muscle afferents. ${ }^{9}$ It is a critical element in the activation of masticatory muscles. ${ }^{10,11}$ Sessle et al demonstrated that stimulation of jaw muscle afferents excites neurons in the $V_{c},^{5}$ and that nociceptor afferent impulses from muscles produce a long lasting central sensitization. ${ }^{12}$

\section{DISCUSSION}

The first suggestion that sensitization of the $V_{c}$ may be important in the pathophysiology of migraine was made by Strassman et al in 1996. ${ }^{13}$ Subsequent research has validated this hypothesis. ${ }^{14-18}$ Sensitization of the $V_{c}$ is

\footnotetext{
Author affiliations:

1. Elliot Shevel, BDS, DipMFOS, MBBCh., Medical Director, The Headache Clinic.

Corresponding author: Elliot Shevel

Medical Director, The Headache Clinic, Private Bag X2600, Houghton 2041, Johannesburg, South Africa.

Tel: +27 (0)82555 5763 Email: drshevel@theheadacheclinic.net
}

\author{
ACRONYMS \\ NS: $\quad$ Nociceptive Specific \\ Vc: Trigeminal Subnucleus Caudalis \\ WDR: Wide Dynamic Range
}

now widely accepted as important in the generation of migraine pain, particularly in the later stages of the acute attack and in the development of chronic migraine. ${ }^{19}$ Sensitization of the $V_{c}$ is important not only in the maintenance and exacerbation of acute migraine attacks, ${ }^{14,20-22}$ but it is also thought to contribute to migraine becoming chronic. ${ }^{23}$

Myofascial trigger points are hyper-irritable spots in skeletal muscle, that are painful on compression. ${ }^{24}$ They are a common finding in migraineurs, and in most cases, compression of the trigger points elicits pain which exhibits typical migraine features. ${ }^{25}$ Trigger point palpation provoked a full blown migraine attack in $29.6 \%$ of migraineurs and the number of individual migraine trigger points was found to be directly related to both the frequency of migraine attacks and the duration of the disease. ${ }^{25}$

Nociceptive inputs from trigger points produce continuous afferent bombardment of the $V_{c}$ and activation of the trigeminovascular system, contributing to the initiation and perpetuation of migraine pain. ${ }^{26,27}$ It has been shown that during a migraine attack, $100 \%$ of patients have sensitivity to palpation of the pericranial muscles, which include the jaw muscles. ${ }^{28}$

The $V_{c}$ plays a crucial role in craniofacial nociceptive transmission, including receiving stimuli from convergent cutaneous and jaw muscle afferents, ${ }^{9}$ and from muscle nociceptor afferents which produce a longer-lasting central sensitization than do those that innervate skin $^{12}$ or dura. ${ }^{29}$ Sensitization of muscle nociceptors leads to a lowering of the mechanical threshold into the innocuous range, and hyperexcitability of dorsal horn neurons, resulting in prolonged neuronal discharges, increased responses to noxious stimuli, and expansion of the receptive field..$^{30-32}$

Treatment of migraine with intra-oral appliances designed to reduce muscle tension in the craniomandibular muscles has been shown to be effective in reducing the severity and frequency of migraine attacks, often eliminating them altogether. ${ }^{33-36}$

\section{CONCLUSION}

The evidence suggests that jaw muscle afferent input contributes to central sensitization of the $V_{c}$ in migraine. 


\section{References}

1. Burstein R, Yarnitsky D, Goor-Aryeh I, Ransil BJ, Bajwa ZH. An association between migraine and cutaneous allodynia. Ann Neurol. 2000;47:614-24.

2. Burstein $R$, Collins $B$, Jakubowski $M$. Defeating migraine pain with triptans: a race against the development of cutaneous allodynia. Ann Neurol. 2004;55:19-26.

3. Levy D. Migraine pain and nociceptor action - where do we stand. Headache (Headache Currents) 2010;50:909-16.

4. Olesen J, Burstein R, Ashina M, Tfelt-Hansen P. Origin of pain in migraine: evidence for peripheral sensitisation. Lancet Neurol. 2009;8:679-90

5. Sessle BJ, Hu JW, Amano N, Zhong G. Convergence of cutaneous, tooth pulp, visceral, neck and muscle afferents onto nociceptive and non-nociceptive neurones in trigeminal subnucleus caudalis (medullary dorsal horn) and its implications for referred pain. J Pain. 1986;27:219-35.

6. Yokota T, Koyama N. Response evoked in the caudal medulla by stimulation of neck muscle afferents. In: Matthews B, Hill R, eds. Anatomical, Physiological, and Pharmacological Aspects of Trigeminal Pain. Amsterdam: Exerpta Medica; 1982, pp. 103-118.

7. Amano N, Hu JW, Sessle BJ. Responses of neurons in feline trigeminal subnucleus caudalis (medullary dorsal horn) to cutaneous, intraoral, and muscle afferent stimuli. J Neurophysiol. 1986;55:227-43.

8. Shankland WE, $2^{\text {nd }}$. The trigeminal nerve. Part I: An over-view. Cranio. 2000;18:238-48.

9. Sessle BJ. Recent insights into brainstem mechanisms underlying craniofacial pain. J Dent Educ. 2002;66:108-12.

10. Tsai CM. The caudal subnucleus caudalis (medullary dorsal horn) acts as an interneuronal relay site in craniofacial reflex activity. Brain Res. 1999:826:293-7.

11. Tsai CM, Chiang CY, YU XM, Sessle BJ. Involvement of trigeminal subnucleus caudalis (medullary dorsal horn) in craniofacial nociceptive reflex activity. J Pain. 1999;81:115-28.

12. Wall PD, Woolf CJ. Muscle but not cutaneous C-afferent input produces prolonged increases in the excitability of the flexion reflex in the rat. J Physiol. 1984;356:443-58.

13. Strassman AM, Raymond SA, Burstein R. Sensitization of meningeal sensory neurons and the origin of headaches. Nature. 1996;384:560-4.

14. Burstein R, Cutrer MF, Yarnitsky D. The development of cutaneous allodynia during a migraine attack clinical evidence for the sequential recruitment of spinal and supraspinal nociceptive neurons in migraine. Brain. 2000;123 (Pt 8):1703-9.

15. Aurora SK, Cao Y, Bowyer SM, Welch KM. The occipital cortex is hyperexcitable in migraine: experimental evidence. Headache. 1999;39:469-76.

16. Grosser K, Oelkers R, Hummel T, et al. Olfactory and trigeminal event-related potentials in migraine. Cephalalgia. 2000;20:621-31.

17. Nagel-Leiby S, Welch KM, D'Andrea G, Grunfeld S, Brown E. Event-related slow potentials and associated catecholamine function in migraine. Cephalalgia. 1990;10:317-29.

18. Siniatchkin M, Kirsch E, Kropp P, Stephani U, Gerber WD. Slow cortical potentials in migraine families. Cephalalgia. 2000;20:881-92
19. Dodick D, Silberstein S. Central sensitization theory of migraine: clinical implications. Headache. 2006;46 Suppl 4:S182-91.

20. Bendtsen L. Sensitization: its role in primary headache. Curr Opin Investig Drugs. 2002;3:449-53.

21. Silberstein SD. Migraine pathophysiology and its clinical implications. Cephalalgia. 2004;24 Suppl 2:2-7.

22. Goadsby PJ. Migraine, allodynia, sensitisation and all of that. Eur Neurol. 2005;53 Suppl 1:10-6.

23. Kitaj MB, Klink M. Pain thresholds in daily transformed migraine versus episodic migraine headache patients. Headache. 2005;45:992-8.

24. Simons DG, Travell J, L.S. S. Travell and Simons' Myofascial Pain and Dysfunction: The Trigger Point Manual. $2^{\text {nd }}$ ed. Baltimore: Williams \& Wilkins; 1999

25. Calandre EP, Hidalgo J, Garcia-Leiva JM, Rico-Villademoros F. Trigger point evaluation in migraine patients: an indication of peripheral sensitization linked to migraine predisposition? Eur $J$ Neurol. 2006;13:244-9.

26. Fernandez-de-Las-Penas C, Cuadrado ML, Pareja JA. Myofascial trigger points, neck mobility and forward head posture in unilateral migraine. Cephalalgia. 2006;26:1061-70.

27. Giamberardino MA, Tafuri E, Savini A, et al. Contribution of myofascial trigger points to migraine symptoms. J Pain. 2007;8:869-78.

28. Tfelt-Hansen P, Lous I, Olesen J. Prevalence and significance of muscle tenderness during common migraine attacks. Headache. 1981;21:49-54.

29. Bolton S, O'Shaughnessy CT, Goadsby PJ. Properties of neurons in the trigeminal nucleus caudalis responding to noxious dural and facial stimulation. Brain Res. 2005;1046:122-9.

30. Dubner R. Hyperalgesia and expanded receptive fields. J Pain. 1992:48:3-4

31. Hoheisel U, Mense S, Simons DG, Yu XM. Appearance of new receptive fields in rat dorsal horn neurons following noxious stimulation of skeletal muscle: a model for referral of muscle pain? Neurosci Lett. 1993;153:9-12.

32. Dubner R, Ren K. Central mechanisms of thermal and mechanical hyperalgesia following tissue inflammation. In: Bovie J, Hansson P, Lindblom U, eds. Touch, Temperature, and Pain in Health and Disease:Mechanisms and Assessment. Progress in pain research and management. Seattle: IASP Press; 1994, pp. 267-277.

33. Quayle AA, Gray RJ, Metcalfe RJ, Guthrie E, Wastell D. Soft occlusal splint therapy in the treatment of migraine and other headaches. J Dent. 1990;18:123-9.

34. Lapeer GL. Reduction of the painful sequelae of migraine headache by use of the occlusal diagnostic splint: an hypothesis. Cranio. 1988;6:82-6.

35. Lamey PJ, Barclay SC. Clinical effectiveness of occlusal splint therapy in patients with classical migraine. Scott Med J. 1987;32:11-12.

36. Shevel E. Craniomandibular muscles, intraoral orthoses and migraine. Expert Rev Neurother. 2005;5:371-7. 